\title{
Applying Multilogical and Metamemetic Approaches to Understand How We Think and Feel in Space
}

\author{
Monique Cardinal \\ Library and Information Services, Kingston, USA \\ Email: coralmelonsage@gmail.com
}

How to cite this paper: Cardinal, $M$. (2021) Applying Multilogical and Metamemetic Approaches to Understand How We Think and Feel in Space. Intelligent Information Management, 13, 232-249. https://doi.org/10.4236/iim.2021.134013

Received: June 8, 2021

Accepted: July 27, 2021

Published: July 30, 2021

Copyright ( 2021 by author(s) and Scientific Research Publishing Inc. This work is licensed under the Creative Commons Attribution International License (CC BY 4.0).

http://creativecommons.org/licenses/by/4.0/

\begin{abstract}
First, this paper suggests a hypothetical formula that aims to explain how we are conditioned to think. Finding different ways to think about relevant decisions and problems through multilogical approaches could help make the decision-making or problem easier to understand and manage than any conventional one-directional way of thinking (or monological thinking). Secondly, one theory to help understand the quality of how we think is through associating ideas of reality with what we observe. This is helpful through a theory such as Memetics, or the study of memes (and evolutionary replicator points [genes, memes, tremes]), as coined by Richard Dawkins in his 1976 book, The Selfish Gene, and proposed by other authors including Dr. Susan Blackmore ("The meme machine", 1999). Plenty of indications and evidences seem to show how we are entering the third replicator point (technomemes), consisting in a psycho-sociological process of merging human beings and societies (memeplexes) with technological advancement. Digital and non-digital relationships to our values/ideas/ideologies and beliefs make us think differently and often via manners that can damage our reasoning skills and proper ways to process information (see problematic topics such as "post-truth era", disinformation, information overload, anti-science and anti-intellectual trends, conspiracies and so on), but we still do not have any educational and/or individual training to understand critically and apply such an understanding in such relationships (through states of mind). This paper intends to explore a theory of Metamemetics and Multilogical Thinking theorized by Diego Fontanive (https://en.wikipedia.org/wiki/Memetics see: ${ }^{\star}$ terminology, see: ${ }^{\star}$ Metamemetic thinking). Lastly, this approach is explored and applied with examples of approaches to problems people hypothetically have. This exploration is put into the context of space exploration and studying the psychology of individuals who are in solitary situations for long periods.
\end{abstract}




\section{Keywords}

Groupthink, Memetics, Metacognition, Psychology of Space Exploration, Space Programs

\section{Introduction}

If applied critical thinking is lacking, how can it be approached and applied in situations and environments of uncertainty? Operant conditioning is pivotal to understand how our thinking is conditioned. A theory of conceptualizing emotions is mentioned to support this author's reason to focus on memetics. The main approach includes multilogical thinking, metamemetics, and meta-meta cognition (see glossary), terms coined by Diego Fontanive

(https://en.wikipedia.org/wiki/Memetics). Other theories that are cited refer to psychology, space research, and group dynamics. In the appendices, a list of potential future topics for research is aimed to find areas of conditioning that may need to be understood differently, thoroughly, and accurately with ways to manage them psychologically. Conditioned aspects (cognitive filters in appendices) include values, beliefs, and epistemic acceptances.

\section{Psychological Conditioning}

Locational and psychological constructionist theories are two approaches to categorizing how the brain decodes emotions (Lindquist, et al., 2012). The first theory hypothesizes that emotional categories-like fear, anger, entrancement, craving, confusion, and nostalgia-correlate with particular regions of the brain, which the authors found little evidence for. They found more evidence for the second theory, which proposes that there is more overlapping between roles of different brain networks. This led to various emotion categories (Lindquist, et al., 2012). A third theory is the appraisal approach, which theorizes that different areas of the brain contribute to a diverse range of emotions and are activated when we have experiences and give attention to what we observe.

Conceptualization is the process by which stored representations of prior experiences (i.e., memories and knowledge) are used to make meaning out of proceeding sensations. Categorizing gives meaning to what is interpreted, and its differentiation may be helped by Memetics (the study of how meaning-replicators work). This happens, for example, with moralizing behaviors. We use ideas we become familiar with, but we do not usually think about ideas that created current ideologies. To prevent or reduce potential issues, we might need to think differently about what is observed to avoid issues [1].

An appraisal model theorizes that there is an automatic meaning associated with an emotion triggered by stimuli or cognitive mechanisms. These cognitive mechanisms include identification, idealization, reaction formation, interjection, disassociation, projection, symbolization, trivialization, somatization, and deni- 
al. These are behaviors we are not always aware of and that are not always deliberate. Knowledge of these models will help with theories regarding origins of meaning-making (such as Memetics) and correlating thoughts and meanings (such as with psychological pictures, which will be explained later).

Regarding the proclivity of how people think, a hypothetical approach supported by the notion of operant conditioning and neurological patterns might support why it is crucial to improve thinking skills in situations such as a future in which generations will likely be an extraplanetary (and even interstellar) species.

Formula (approach) 1: [conditioning $\times$ frequency of neglected details - inquiry] $\times$ recollection of peaks and ends of an experience later in life - inquiry $=$ imitation/emulation ( ${ }^{*}$ Peak - End Effect/Fallacy: remembering the ups and the downs only, and the way they ended, but without inquiring into the dynamics of the passages that lead to the ups, the downs, and their end).

This equation-approach theorizes how every human being is inevitably conditioned. It is mainly associated with operant conditioning (See Pavlov experimentation) which, psychosocially speaking, takes place in the form of what we can describe as "punishment/reward cognitive imprinting".

A procedure is repeated for us to follow until we have it ingrained in our thinking and behavior. We are not prone to ask or be encouraged to ask why we should do this procedure, especially during the early stages of childhood where the cognition and intellectual/cognitive/cerebral capabilities of the child are still in development. For procedural knowledge to be remembered, we create and rely on meanings, (which, when collectively accepted, become de facto epistemic acceptances), and usually, in doing so, details are left out.

Future scenarios are not considered critically and logically, but rather are pictured in ways that are conditioned by the fact in which most people think by analogy instead of what is known as "first principles thinking". Peak end effect fallacy and other biological limitations like implicit biases and inattention biases are important factors of illogical thinking.

Duration neglect bias can lead to mistakes in processing information and quickly using the memory of previous experiences to make decisions. We can't predict the future, but it can be prepared for by alleviating feelings of immense panic in response to a disaster. This is due to normality bias, which is the proclivity to predict what will happen using a calculation based on what has already happened and what is known so far. The application would be conditioned by our memories and past experiences, and beliefs, and monodirectional thinking procedures. The last two conditioning mechanisms are exemplified by predicting cars would fly, but not seeing the advent of the internet, allowing for global communication.

Neurologically, rewards are associated with dopamine production in the brain, which we strive for due to massive cultural conditioning, especially in the western world. We do not crave chemicals linked to anxiety and fear. Seeking rewards is linked to the desire to feel safe. The process of getting rewarded causes a de- 
crease in thinking skills or increase in laziness (D. F., personal communication with author, 2020).

How we perceive the world can be an obstacle to refining our thinking, but there are interesting situations where a question comes about how conceptualization impacts thinking if a thinker does not allow the interference of memes throughout the process of thinking itself. Someone who interacts with another person who may not decode the value of necessary metamemetic criticism of meanings involved in meme-concepts, like love for example, may categorize the conversation/interaction as something that requires deeper analysis and better mutual understanding. Understanding things for what they are requires a different and higher intellectual process, such as an evolving theory by Howard Gardner, on multiple intelligences. This theory is important, but another theory, Memetics, will be discussed, and a few terms will be applied to of exploring the way we think and decode emotions and how they relate to meaning-making.

\section{Evolutionary Replicator Points}

In 1979, Richard Dawkins wrote The Selfish Gene, comparing the fecundity, fidelity, and longevity of genes to memes. Psychologist Susan Blackmore, extended application of the theory of memetics to temes in her book, The Meme Machine, and which has been introduced to digital selves in Book of Abstracts [2]. Before the internet, ideas were sold on a billboard, like an analogy in Richard Dawkins' book. Blackmore aligns Memetics dynamics with temes [3]. She wrote this when blogs were probably the only social media available.

A tragic example about the algorithmic replication in computer algorithms might be hacking. In memetics, the virus would be represented by ideologies that can lead to historical wars and conflicts which are unique to humans, and particularly our genus, Homo Sapiens. This table depicts some similarities amongst genes, memes, and technomemes (see Table 1).

The evolution of meanings depends on memories created in each culture. Some critics from social science consider this theory a generalization about cultural values. For more information on Memetics, the Memetic Compendium includes a collection of related data.

\section{Examples of Multilogical Understanding and Metamemetic Approaches}

The main theory that is discussed here involves studying the connection between and amongst thought processes is a combination of metamemetic (thinking about memetic viruses), Metametacognition (thinking about our conditioning), and multilogicality (understanding something via different perspectives). Metacognition is counteracted with limits of the inability to think about our thinking, multilogicality counteracts with monological thinking, and Metamemetics goes beyond the study of belief systems (in the field of Memetics) to study how memes create violence. 
Table 1. Comparing genetic, memetic, and digital evolutionary replicator points.

\begin{tabular}{|c|c|c|}
\hline Genes [4] & Memes & Temes \\
\hline $\begin{array}{l}\text { Propagation-Capacity } \\
\text { for traits to spread. }\end{array}$ & $\begin{array}{l}\text { Ideas are recorded, given } \\
\text { as suggestions, marketed } \\
\text { as rhetoric, etc. }\end{array}$ & $\begin{array}{l}\text { Tagging/tracking cookies records } \\
\text { users' visits to a site. Another } \\
\text { example is cataloging information } \\
\text { that will be seen and shared. }\end{array}$ \\
\hline $\begin{array}{l}\text { Fecundity-Information } \\
\text { is successfully stored } \\
\text { as DNA. }\end{array}$ & $\begin{array}{l}\text { Ideas are accepted } \\
\text { regardless of inquiry. } \\
\text { Also, we aren't wired to } \\
\text { remember things } \\
\text { accurately. }\end{array}$ & $\begin{array}{l}\text { AI is currently not self-regulated, } \\
\text { which is a current question in } \\
\text { research. Nanotechnology is one } \\
\text { advance in storage of information. }\end{array}$ \\
\hline $\begin{array}{l}\text { Mutations are copied } \\
\text { when DNA is copied. }\end{array}$ & $\begin{array}{l}\text { Even when there is an error } \\
\text { in the framework of } \\
\text { thinking or behavior or } \\
\text { ritual, the brain can still } \\
\text { function. }\end{array}$ & $\begin{array}{l}\text { If a code has an error, the } \\
\text { algorithm is broken. }\end{array}$ \\
\hline Biological, self. & $\begin{array}{l}\text { We have healthy and } \\
\text { unhealthy ideas about } \\
\text { ourselves, filtered via } \\
\text { cognitive tools such as } \\
\text { creativity and imagination } \\
\text { which are memetic. }\end{array}$ & $\begin{array}{l}\text { Digital selves allow us to alter what } \\
\text { others see and manifest what we } \\
\text { wish others could see, giving a new } \\
\text { kind of self-esteem. }\end{array}$ \\
\hline
\end{tabular}

Furthermore, with the relationship to meanings, a term Fontanive created is psychological pictures, which concerns Theory of Mind. Psychological pictures are active memes acting as and with cognitive filters, not to be confused with pareidolia, (where the brain detects patterns that are familiar to it and then interprets something that is not there, like a face in a cloud (D. F., personal communication with author, 2020). Based on theory of mind, knowledge and mindset are associated with meanings (memes) that we adopt into our thinking when we are interacting with others and between thought processes. Multilogical thinking contains first principles thinking: boiling down complex topics to their bottom truths and premises (assuming there are some) to then reason it all up, discarding interferences and bad memes, personal experiences (which have subjective interference), beliefs, and opinions.

Psychological pictures give authority to ideas we have about the world and people (D. F., personal communication with author, 2020). A dominating characteristic is associated, such as with what people may expect a mother and son to do, ideas (or expectations) of how their relationship is supposed to be, and what is considered a taboo.

They can be rational, but they can be confused with ideas of what is rational. Though ideas can have authority, someone who associates themselves with authority might resist understanding, critique, or questioning, assuming they are the authority, and they are, from the perspective of the reptilian brain, under attack. The defense mechanism could be a pattern or algorithm, which can give itself authority without us remembering or being able to respond without it being 
a distraction, causing feelings or emotions to surface. Here is a list of sample questions and approaches to see how analysis of thinking can lead to a progressive understanding of an issue or object of confusion (see Table 2).

\section{Strangers, Groupthink, and Space Research}

Algorithmic thinking helps explain relationships between our thought processes and amongst group members, which are called memeplexes, which might explain the agreeable type of groupthink. Algorithmic thinking is based on memories (which represent the structure of what we know) and is based on and influenced by combining past and current information processing. This includes personal systems of preferences regarding emotions, morals, ideals, wants, things to avoid, likes and dislikes. It also highlights the structure behind how our selective reasoning works, depending on the degree of awareness and attentiveness, psychological and cultural conditioning, management of distractions, cognitive dissonance, notional knowledge, and metaignorance. The way we are biologically wired and our physical reactions to environmental or sociological stimuli is important. We also produce psychological and actual (physical) behaviors that affect emotions caused by meaningful influences and outcomes. Instincts, intuition, or feelings take place in the absence of knowledge when we do not have enough accurate information about different subjects or topics, which is compromised by being associated with our knowledge base. Our algorithmic thinking is conditioned by the memeplexes we are living in such as family, friends, society, college, in the past and currently.

Studies on obedience by Stanley Milgram, becoming evil by Philip Zimbardo (both having biased and unethical methods as discussed in psychological literature) and bystander theories are examples of experiments trying to understand negative behaviors and entropic group thinking [5]. Another concept attributing to group dynamics is Attribution Theory, which implies the propensity to connect a person's behavior to their character, underestimating the effect of situational factors causing the behavior. It is important to identify and discard irrational thoughts and behavior from rational thoughts and behavior as well as unhealthy from healthy thoughts and behavior.

It is crucial to preserve a solid cohesion and logical cooperation among the members of a space crew and/or a colony on Mars/Moon to avoid or at least maximizes reduction of "groupthink" dynamics. The first type of groupthink is based on expected and increasing agreeableness (among the members of the group). This appears to be a positive condition and development of cooperative human relationships, but (A) by analyzing more inquisitively, analytically, critically, and objectively the psychological and cognitive outcomes of these either short or long run diluted dynamics, and (B) taking into consideration how any system of agreeableness does de facto decrease individual thinking skills [memeplexes are more influentially efficient than single, personal meme replicators], a progressive process of generating and preserving agreeableness and 
Table 2. Example of applying multilogical thinking.

\begin{tabular}{ll}
\hline \multicolumn{1}{c}{ Example of Problem } & \multicolumn{1}{c}{ Example of an Approach } \\
\hline $\begin{array}{l}\text { Distinguishing when we want to } \\
\text { understand something as opposed to } \\
\text { wishing to win an argument or get a } \\
\text { drive of some sort. }\end{array}$ & $\begin{array}{l}\text { We should see things from other points of view. Plus, } \\
\text { we should distinguish valid from invalid premises. In } \\
\text { critical thinking, via negative is applying a framework } \\
\text { of thinking that focuses on reasoning on what } \\
\text { something is not instead of what that is. This is } \\
\text { also a form of deductive thinking. }\end{array}$ \\
$\begin{array}{l}\text { Relationship to limitations, } \\
\text { irrationality, need for safety, } \\
\text { uncertainty, etc. }\end{array}$ & $\begin{array}{l}\text { Make a mind map depicting thoughts associated with } \\
\text { emotions and meanings that we correlate and trace } \\
\text { where they came from. Deduct what is rational and } \\
\text { discard what is not. Understand the context. }\end{array}$
\end{tabular}

We have multiple meanings for something, but not an objective understanding.

Knowing when we are not thinking.

Ask what they mean by their definition (especially if they talk about something subjectively defined).

Distinguishing thoughts from thinking is useful. The appendices provide details about the distinctions.

Reduction via... recognizing irrational beliefs contradict rationalized intent. One group of people

Implicit biases.

Unnatural guilt.

Identifying unhealthy thought processes feelings associated with them, such as fabrication of stories.

Feelings imply a lack of information about the objects or subjects that we have a feeling about.

Polarizing groups.

Inability to distinguish unnatural causes of fear from natural. might be ignorant about what another group thinks about something, for example how much they value a cultural norm.

Identify an alief as it arises with help of lateral thinking.

Map structure thought processes and trace the way the processing information works. Metacognition, or thinking about connections between thoughts, conditioned beliefs, or fears and how it relates to societal expectations might be a beginning to separate reality from manifesting ideals.

This implies the condition in which in most cases, instead of attempting the process of gathering more information, we rather tend to compensate for the lack of data with a production of assumptions which includes so commonly confirmation bias/based mindsets, cognitive dissonance, and wishful/magical thinking too. A rational administration of both "psychological time" (the way through which we manage the cognitive speed we use throughout our act of thinking) and information help make more logical observations.

Becoming a polarized group identified with an opponent group is an example of the author of the mind taking shape. We might make stereotypes and ideals to become and create labels to build a sense of familiarity.

Unnatural versus natural causes of fear, ideas, meanings associated which can come quickly and sneakily Relationship to desires, uncertainty, values, public, mistakes, becoming our ideal something (see "authors of the mind" in the glossary). 
harmony among the group members causes and feeds a process of focusing on the willingness to preserve that state of cohesion more than anything else. This is and will lead to a considerable problem consisting of a directly proportional increase of inattention regarding discussions, questioning analyses, and a fundamental lack of clarity required to highlight salient issues, problem-solving methods, effective strategies for making. In a planetary colony, this can lead to lethal results if a situation is not looked at multilogically.

The second type of groupthink is the opposite of the first one, consisting of an increase of "entropy" in the group caused by progressively divergent ideas and viewpoints, the formation of sub-groups, and the rise of frictions/tensions. This process activates a series of interpersonal factors that easily generate a quick or gradual escalation and desegregation of patterns in the group itself. In an environment like a Lunar base or Mars colony, this can be serious or even catastrophic.

Performance, conduct, and behavior have aspects connected to values in a culture [5]. One origin of disagreement comes from conditions caused by Nationalistic operations of standards and values. Can a counteraction be made by globalization, AI, and a decentralized economy? Strangers do not have psychological pictures about each other, but the unknowns are filled in by memetic thinking informed by the known and personal subjectivity (personal ideas, beliefs, cultural differences, even prejudices, stereotypes, and hopefully mild dogmatic proclivities). Cultural sensitivity is increased through cultivating rational and sound accurate awareness, while personal sensitivity is reduced by polarization and stereotyping.

An embodiment of values creates an identity which is exemplified in Erik Erikson's psychosocial stages of development. Suedfeld \& Brcic found that there are more favorable than unfavorable outcomes of psychosocial stages of development listed by Erik Erickson. Those stages are trust versus mistrust, autonomy versus shame, initiative versus guilt, industry versus inferiority, identity versus role confusion, intimacy versus isolation, generativity versus self-absorption, and integrity versus despair. Some observations about the outcomes of critical scenarios are applied. This article discusses changes due to variables of and flight phases. Across the phases, there is a steadily increased pattern of integrity over time. In one sample regarding a group of 97 people, 54 were from the U.S., 30 from Russia, and 13 from other countries. 79 were male, while 18 were female [6]. Russia was ranked higher in industry, autonomy, and initiative than other countries, lowest in identity and integrity. Other countries were ranked higher in identity outcome than the U.S. and Russia, lowest in autonomy. The U.S. and other countries are close in rank for industry and initiative; about half to one-third of Russia's ranking for those categories.

The astronauts were building and maintaining new relationships in the months spent together and, in some cases, referred to their crew intimately. One article recommended the need for more socialization in a 90 -day mission. $40 \%$ of 
members reported a conflict, though no more than 6 were reported in a month [7]. There was inconsistent written communication between the mission commander and crew over time and inconsistency of mood dynamics in this study.

Can we hypothetically apply self-evaluation if we consider the reality of emerging with something we are uncertain about, even when we have relevant data, about our limits, and in terms of preparedness? Are there fallacies in the applications of using a psychological theory?

Evidence shows that there is more cohesion in groups with mixed genders than in having one gender. There are social constructs that interfere with ideas about sex, but there are mainly practical and biological differences, like physical strength.

There are social constructs that interfere with ideas about sex, but some mainly practical and biological differences, like physical strength. There are some case studies in space simulation environments for social constructs interfering with task performance and psychology. Privacy elimination, separation from family and friends, and delayed communication are among crucial problems that are not anticipated. Faulty judgment and miscommunication were consequences of losing Columbia and Challenger [5]. A small team size is growing, more diversely (multicultural), and longer missions encourage changing, holistic approaches to behavioral research. Collaborative efforts have switched from previously competing for nation-specific space crews.

\section{Implications of Group Dynamics in Space}

Evidence supports that how we think and decisions we make will need to adapt, if possible, to changes in the future. Group-based concerns include management of arguments putting the entire crew at risk, firing a member, romantic relationships, and beliefs. Possible outcomes of decisions must be predicted and prevented in various ways, through dynamic, lateral, or otherwise critical approaches in case there are severe disagreements.

Additionally, (despite this point being controversial for some people): the crew should not have religious people on board because despite the likelihood of nothing happening, nevertheless having some religious crew members can summon a potential risk. Summoning potential risks are antithetical to any protocol on which any space mission is based. (Moderate) religious people can eventually be part of planetary colonies but should not be among pioneers' crew teams (D. F., personal communication with author, 2020). Romantic relationships among crew members: This should be avoided too when the crew is a crew of pioneers. It will not constitute a problem if it takes place in a large community such as a community of 1,000 people on Mars for instance or on the moon.

Regarding social issues and group dynamics issues, a good leader is someone who can use and apply higher-order thinking skills in the necessary and relevant ways, not out of pompousness or some sort of arrogant means.

The general population is not taught policymaking, and there is no training 
for multilogical thinking in education. On the consequential side, operant conditioning and political correctness distort education. AI project debaters (like the IBM debater computer) can help us make decisions, make policies, by deducting irrelevant and unhelpful information.

Vakoch suggests that when we interface with other people and their mindsets, the premises behind discussion should be divided from opinions and points of view [5]. We also should manage our values, roles regarding our cultural conditioning, and relationships with people, knowing they are conditioned as well.

It would be crucial to run perpetually psychometric evaluations of those who intend to become policymakers (including political candidates and leaders) to evaluate the level of intelligence, unbiased thinking skills, and competence. In this regard, a specific protocol should be applied and must be a methodology aimed at decoding how fallacious a candidate is (distinguishing thinking from their conditioning, which is influenced by ideologies, faiths, beliefs, etc.). This methodology should be supported by blockchain technology to guarantee and monitor the efficiency and integrity of its contents and its methods of assessing people (and the results). This will considerably decrease the problem of biased policymaking, which is a trend that is severely on the rise, internationally speaking. The same methodology must be applied to space exploration where humans are involved.

\section{Environmental and Psychosocial Connection}

Nonsocial issues discussed here include pre-flight training, space simulation, and self-sufficient colonies. Secure communication, earth-like environments, and stable management of overpopulation and longevity are relevant concerns. Nanotechnology and AI development should be considered in this research as well.

A technological issue connected to pre-flight training, and some considerations include the length of preflight training: pacing of steps, testing whether assistance makes the training more effective and what further protocols to implement, and noting the effective approaches in preflight training while acknowledging and discarding the limiting or less effective approaches. What variables that can enhance the effectiveness and duration of space flight missions?

Space environment simulations are designed to prepare potential candidates living in lunar colonies. These are engineered to be compatible with the capabilities and desires of users. Designs of an apparatus could be better paired with what users are able and wish to do. A simulated space environment will allow an experience in a space-like environment without risking safety. How we think about and study people's behavior in space vehicles can be a goal in an experiment under the European Space Agency, which invited volunteers to experience space stimulation for 520 days [5]. Missions to Mars and the moon will have up to eight people.

In a simulated environment, astronauts perform tasks in caves and stations, low-earth orbit. Observations are made about the effect of lack of circadian 
rhythms, spatial navigation, perception, interaction, performance stress. A question of disaster preparedness and relating to the unknown would be questionable [6].

Self-sufficiency in space exposes the crew to space radiation which can penetrate the spacecraft. The exposure along one month of cosmic radiation can reach ten times or more the normal exposure we tolerate on earth along one year. This risk can affect the crew's cognitive abilities and can cause mental illnesses. One way to avoid this is to increase the thickness of the spacecraft's walls. However, the heavier the craft is, making the craft reach escape velocity and escaping the critical mass point during the launch will become progressively difficult unless the craft is directly built-in space eventually using industrial space 3D printers. Despite having this technology already, the costs to build something like that would be incredibly high.

Another solution is to add water within an inter-space contained inside the spacecraft's walls. This is probably the most economic solution, precisely because water is one of the best elements to block cosmic radiation. Still: this is a bit of a problem regarding the craft's escape velocity during launch. The possible option is to build the spacecraft directly in space, or even better on a Moon base once available, considering how easier it is to reach escape velocity on a planet that has no atmosphere and low gravity.

However, the optimal choice regarding building bases on Mars (in particular) consists in sending material aimed at constructing structures and habitats using space vehicles that are completely automatic and capable to reach Mars and operate in loco with no human crews.

Such machines must also be able to extract needed material directly on Mars to produce self-development. Once people begin to join the colony in which basic structures and endurable habitats are set, the colony must be completely self-sufficient and capable of sustaining itself in every sense, without relying on cargo missions from Earth. The reliance on cargo missions from Earth (such as supplies, food, material, medical equipment, and so on) is simply unsustainable on Mars, not just prohibitively expensive. Another goal is to find a geologically similar environment on an Earth-like planet. What can be grown on Mars, and can systems like underground production on earth be replicated with effective results in exoplanets?

Conclusively, environmental issues also will blend with psychological issues. Due to many factors like coexisting for a long time in a small, protected environment or a member experiencing severe depression, even suicidal thoughts: this possibility should be strictly prevented.

\section{Conclusions}

This paper suggests ways to look at how we are conditioned to think and pause to analyze any flaws in the process of thinking. New theories and approaches can be explored with regard to understanding what can be understood and acknowl- 
edging limitations while discarding what cannot be understood. How can we remove ourselves from the cognitive interference of psycho-social toxic conditioning and unnecessary/dysfunctional thoughts, emotions, and social-historical interferences in general?

If we eventually grow close to the integration with $\mathrm{AI}$ and become an interplanetary/interstellar species, multilogicality and metamemetic training is crucial. Responding to change is harder when relying on our thinking considering how our brain, especially the limbic system, is substantially the same brain we had during the Stone Age. What would be the outcome of responding to the environment when applying different methods of applied critical thinking, alone and in groups?

To conclude, three theories of emotions are mentioned-Locationalist and Psychological constructionist theories. Three replicator points are comparedgenes, memes, and technomemes. A combined approach of Multilogical and metamemetic thinking and a combined theory of meaning, psychological pictures, are introduced. Examples of approaches are listed, group dynamics explored, psychosocial and environmental changes as issues in space research. A glossary of relevant terms and observations of a sample survey on values and critical thinking are included in the appendices, encouraging further understanding, discussion, research, and theories.

In further discussion, it would be worth exploring methodologies and platforms (if online) for training and the result of training in Metamemetics and delegation and personal inquiries about biased thinking (examples in appendices). Research should be collected and studies should be conducted on intervening with biased policymaking, self-critical analyses, and managing terminated members during spaceflight missions. A mission would be at risk without considering factors that impact psychology and behavior.

This paper lacks extended, primary research blending applied critical thinking in areas where there is uncertainty between people as well as information processing and thought processes (as well as between thought processes). To find ways in which the futile scenarios can be responded to is a goal for future decision-making.

\section{Acknowledgements}

I wanted to express appreciation for help from anonymous reviewers and editors, and Diego Fontanive for contributing in revising and critique.

\section{Conflicts of Interest}

The author declares no conflicts of interest regarding the publication of this paper.

\section{References}

[1] Lindquist, K.A., Wager, T.D., Kober, H., Bliss-Moreau, E. and Barrett, L.F. (2012) The Brain Basis of Emotion: A Meta-Analytic Review. Behavioral and Brain Sciences, 35, 121-143. https://doi.org/10.1017/S0140525X11000446 
[2] N/A (2019) Book of Abstracts. 4th Avant Conference 2019: Trends in Interdisciplinary Studies, Porto, 24-26 October 2019, 25-26.

[3] Susan, B. (2000) The Meme Machine. Oxford University Press, Oxford.

[4] Richard, D. (1979) The Selfish Gene. Granada Publishing Limited, London.

[5] Suedfeld, P. and Brcic, J. (2011) Resolution of Psychosocial Crisis Associated with Allying in Space. Acta Astronautica, 69, 24-29. https://doi.org/10.1016/j.actaastro.2011.02.011

[6] Bell, S.T., Brown, S.G. and Mitchell, T. (2019) What We Know about Team Dynamics for Long-Distance Space Missions: A Systematic Review of Analog Research. Frontiers in Psychology, 10, Article No. 811. https://doi.org/10.3389/fpsyg.2019.00811

[7] Mogilever, N.B., Zuccarelli, L., Burles, F., Iaria, G., Strapazzon, G., Bessone, L. and Coffey, E.B.J. (2018) Expedition Cognition: A Review and Perspective of Subterranean Neuroscience with Spaceflight Applications. Frontiers in Human Neuroscience, 12, 407. https://doi.org/10.3389/fnhum.2018.00407 


\section{Appendix A: Glossary}

Alief (coined by Tamar Gendler in 2008): Automatic or habitual belief-like attitude. We might eat something we think is not safe because it looks gross or not go near a room made of glass. Aliefs and reverential fears are fueled by memeplexes. Aliefs can also be memetic and based on memetic thought processes. Such as an experiment aimed at testing people's level of superstitious thinking is asking people to create a voodoo doll, placing a photo of a loved one on the doll's head, and puncture the doll with a needle. Most people are prone to feel some mild discomfort even if they know it is all irrational. The most common alief is the fear of flying using planes.

Algorithm: A process or set of rules to be followed in calculations or other problem-solving operations, especially by a computer. Also, a system aimed at creating a path that is supposedly inspired and assisted by one's proclivities and interests.

Amygdala: Part of the brain that responds instinctively to apparent or memetic dangers. The brain can not differentiate chemicals that are from natural versus unnatural causes (unnatural being memetic in this case). The brain cannot differentiate between what's real and what's not. The amygdala is also responsible for imagination and motion.

(Hypothalamus/prefrontal cortex) reactions and responses are interfered with via how we manage the input of information and perceive a stimulus, including reducing response or reaction to changes processed in the skeletal system, affecting behavior patterns.

Analytical thinking: Takes things apart to analyze connections and dynamics of each part as well as the purpose.

Antidarwinian: A phase in human evolution where we have established a livelihood and existence through means not previously executed. Most of the things we think and do are indeed non-Darwinian (like having a voice call using a device for instance, or creating music and art).

Assimilation: The process of taking in and fully understanding information or ideas distinguished from imitation. Assimilation can be performed using sound accurate information processing or not. In the second case, it becomes cognitive conditioning.

Authors of the mind/authority: We give ourselves rules, ideas, beliefs, expectations, label things as a range of values based on experience, relevance, importance, etc. We have expectations about things based on experiences and conclusions made from previous, similar experiences. We store these ideas in psychological pictures.

Bias: Belief (or mere proclivity) favors for or against something that becomes a form of prejudice. If something becomes a fact, such as a verifiable fact, the belief inherent in that fact is indeed no longer required. For instance, we do not say nor even think stuff like "I believe in a microwave": the microwaves just are what 
they are and work or do not. No belief is required.

Competence: The ability to do something successfully or efficiently due to a high level of understanding and knowledge about the subjects (distinguished from "confidence"). Psychological competence is also based on good serotonin levels, which make us managerial.

Confidence: The feeling or belief that one can rely on someone or something; firm trust. The Dunning Kruger Effect is fundamentally based on confidence that is not inquired. This is why it is also called the "confident idiots effect". Confidence is based on dopamine.

Confirmation bias: "We might skip over the information and potential arguments that do not help our beliefs. We take only the information that helps us, and sometimes we take that out of context or neglect reading to see that the contents of that information are relevant or helpful as well (Fontanive, 2019).”

Critical thinking: Objective analysis and evaluation of an issue to form a judgment, the key is to find new methodologies to make it work.

Deductive reasoning: Using a set of data or facts to come up with another sound accurate and plausible set. Deduct facts from facts, so you know the process ends with facts. This should be valued more than inductive because of the reality and contagiousness of confirmation bias. Deductive keywords have a sense of hesitation or doubt (maybe, we will find out eventually, probably, depends, perhaps, etc). Example: The legalization of marijuana might help in medical cases but depends on how it is used and the entirety of the procedure and outcome.

Dynamic thinking: This entails identifying, applying, through labels, ideals, expectations, distractions, etc. Example: applying the mechanism of how one loses religion to losing diet or an obsession/addiction to gain something needed like security. Separating ideas of how to get this should be distinguished from how to rationally get that.

Emotion: A component of a neurotransmitter, "natural instinctive state of mind deriving from one's circumstances, mood, or relationships with others."

Fallacy: Mistake in the reasoning process and making an argument.

Feeling: A lack of decent amounts of information about something, also informed by limbic reactions.

First principles thinking: Boiling premises down to basics to analyze them.

G. I. Joe bias: We might assume that knowledge is half the battle. Need application, understanding, tweaking, trials, critiques, etc. if knowledge is objective, then it must be taken into consideration that we are always subjective. Only a certain amount of knowledge, also, is technically needed for the brain to manage itself. Most of our knowledge is not technical, and likely must be subjective (D. F., personal communication with author, 2020).

Idea: Perceive a pattern of thought pattern, more aware of than other thoughts.

Ideology: (Dynamic of a structure of thoughts and framework of thinking 
focused on and driven by monodimensional ideas or beliefs, also is analogous to religion and magical thinking, regardless of faith and transcendental beliefs are involved or not): the set of ideas, one of many psychological pictures and monodirectional.

Ignorance: Lack of knowledge that can be fulfilled by knowledge via learning and understanding.

Irrationality: Natural illogical response/(limbic) reaction.

Imitation: The action of using someone or something as a model.

Inattention bias: We become oblivious to other possible elements around the object we focus on the details if we narrow in on one, and miss the whole picture also. If we narrow in without acknowledging others and analyzing anything possibly interacting, lose track of the actuality of what we observe. Become twisted to define a type of nightmare), the event will happen. This assumes comparative mythology is a reliable source for facts.

Information ecology: A memetic and/or digital environment (brain and mind) processing and reacting to the environment and other people with different physiological pictures.

Lateral thinking: An indirect and creative approach to progress.

Memes: Units of culture replicating in the mind that twist ideas and apply meaning with information. There are helpful memes such as art, symbols for the pharmacy, egg carton boxes, paying for goods. There are unhelpful memes such as indoctrination, common sense, assumptions, and expectations.

Memeplexes: Groups of people with memes In common (family, friends, institution) that are stronger with rituals, physical structure, language, narrative, norms, etc. held under macromeme (like monotheism) with followers and leaders (selfplex). We are also memeplexes as we are a combination of often contradictory memes.

Memetic virus: While genes do not jeopardize the host (the animal that carries those genes), memes instead can do that, while attempting to proliferate and replicate. The kamikazes in the Jihad for instance, or in Japan during WW2, or suicidal thoughts caused by an identity crisis, are all memetic viruses capable of killing the host that carries such memes and keeping them unreasoned (Fontanive, 2019).

Memetics: Study of how memes work.

Metamemetics: Diego Fontanive's adaptation of Memetics, studying the viral memes and violence caused by devotion to them. "It also involves the decoding of the premises behind the meaning of the meaning to understand whether the premises are valid or not (Fontanive, 2020)."

Metametacognituon: Thinking about the structure of thinking behind our conditioned way of thinking and how it got conditioned.

Metacognition: Thinking without the thoughts that created that way of thinking (monological)-maybe lateral approach.

Metaignorance: Not knowing how ignorant we are about something or eve- 
rything. Meta-ignorance is also a type of Dunning-Krugger.

Moralism: Ideas of right and wrong were created by people's ideas, despite that we get discomfort from assuming what the absence of moralism is, another meme: amoral. Associated with permission (rights) and giving control to someone as an authority (more memes), we feel safe.

Multilogicality: Diego Fontanive's approaches combined with meta understand things from different logical perspectives.

Procedural knowledge: Previous knowledge and experience is applied to finish a task or make a conclusion. They have a set way to get from point $a$ to $b$ to c. It's not something we pay attention to, set on the end goal. Monological thinking would make us have commonly accepted ways to solve problems.

Psychological pictures: Continuously operating filters that we use to interpret the world. Certain filters work for certain things because we were not taught how to identify filters and interact without them to use to see things, like laws, values, norms, problems, values, beliefs, and information.

Religious thinking: The propensity to follow ideas, people, beliefs (epistemic or otherwise), ideals, etc. "Religion" means "to rely on."

Reverential fear: Fear conditioned by memetic infections, imprinting, memetic values, and memeplexes.

Sensemaking: The action or process of making sense of or giving meaning to something, especially new developments and experiences [5].

Stupidity: A psychological behavior that implies the lack of acknowledgment of the magnitude of distractions interfering with our thought processes. Also reiterating dictionary terms: lack of applying skills and knowledge, lack of making sound judgments (resulting from distractions).

Temes (or tremes): Susan Blackmore theorized technological memes are extensions of ourselves, although it seems we are extensions of technology because of such freedom as to be anything we want to show ourselves as. (She has numerous lectures, a website, books, and a ted talk supporting her applications of Richard Dawkins' proposal of memetic in "The Selfish Gene" 1976). (See: "The meme machine" by Susan Blackmore).

Via negativa: "The negative way": finding opposing or alternative arguments or premises related to different findings than those you found (of course by avoiding confirmation bias). 


\section{Appendix B: Themes in Survey Responses}

\begin{tabular}{|c|c|}
\hline $\begin{array}{c}\text { Theme about Responses } \\
\text { in a Survey }\end{array}$ & Summary \\
\hline Ideas/Values & $\begin{array}{l}\text { One value is surrounding the quest for spirituality as a meme. } 13 \\
\text { out of } 21 \text { people say it is more appealing than religion because you } \\
\text { can make up your own rules. Religion indeed has more structure } \\
\text { and it's older, which is why spirituality is so appealing. But } \\
\text { fundamentally they are both pivoted on the propensity to } \\
\text { believe in things that have no evidence of any kind. }\end{array}$ \\
\hline Critical Thinking & $\begin{array}{l}\text { Thoughts are different from thinking. } 12 \text { out of } 21 \text { people } \\
\text { said that one reason was that we give meaning to thoughts. } 11 \\
\text { chose elements of thinking critically that need training and } \\
\text { metacognition is counterintuitive. }\end{array}$ \\
\hline Meta-Critical Thinking & $\begin{array}{l}\text { Another question was in regards to how to think about thoughts in } \\
\text { a belief system without using thoughts to lead them. Cognitive } \\
\text { filters are another term to suit thoughts that created other } \\
\text { frameworks of thinking. }\end{array}$ \\
\hline $\begin{array}{l}\text { Behavioral/ } \\
\text { Cognitive/Intellectual/ } \\
\text { Memetic Stupidity }\end{array}$ & $\begin{array}{l}\text { There are many elements of memetic/behavioral stupidity, not to } \\
\text { be confused with cognitive slurs. } 21 \text { responses were added, and } \\
\text { there could be more than one answer per person selected, } \\
\text { shown in the PPT file, supplementary material. }\end{array}$ \\
\hline Ideas/Values (2) & $\begin{array}{l}\text { One value that was discussed is how freedom might be } \\
\text { misused, and } 14 \text { people responded. There was more than } \\
\text { one option that could be selected. }\end{array}$ \\
\hline Critical Thinking (2) & $\begin{array}{l}\text { Another graph summarized ideas about what is missing from the } \\
\text { field of Critical Thinking. } 10 \text { out of } 21 \text { votes were on thinking } \\
\text { versus thought. } 8 \text { say not usually taught how to listen } \\
\text { properly. } 5 \text { say it is counterintuitive... }\end{array}$ \\
\hline Ideas/Values (3) & $\begin{array}{l}\text { The last chart returns to the argument through } \\
\text { counter-intuitiveness, we can train our minds to change. } \\
52 \% \text { voted to change our minds. } 19 \% \text { said we are } \\
\text { stubborn about our beliefs. }\end{array}$ \\
\hline Ideas/Values (4) & $\begin{array}{l}\text { Regarding groups and ideology, } 21 \text { people responded } \\
\text { regarding unnatural ways to split as opposed to natural. } \\
38 \% \text {. were millennials, } 1 \text { person was from the baby boomer } \\
\text { generation. Demographics can influence the values we } \\
\text { have and the way we think. }\end{array}$ \\
\hline $\begin{array}{l}\text { How We Use the } \\
\text { Internet }\end{array}$ & $\begin{array}{l}21 \text { people responded to reasons on why people may } \\
\text { believe a false narrative online. There could be more } \\
\text { than one answer per person. }\end{array}$ \\
\hline $\begin{array}{l}\text { How we use the Internet } \\
\text { (2) }\end{array}$ & $\begin{array}{l}\text { The next question was about listing problems with how } \\
\text { people use computer algorithms. This reflects the natural } \\
\text { tendency to think based on emotions, not logic. }\end{array}$ \\
\hline Ideas/Values (5) & $\begin{array}{l}\text { Another value that seems overinflated is superficiality. } \\
10 \text { out of } 21 \text { people said that it is more excessive than } \\
\text { less excessively valued today. }\end{array}$ \\
\hline Ideas/Values (6) & $\begin{array}{l}\text { Many factors are causing or caused by biased thinking shown in } \\
\text { peer groups, depicted in the supplementary material. }\end{array}$ \\
\hline Critical Thinking (3) & $\begin{array}{l}15 \text { out of } 21 \text { people rated that people who were being } \\
\text { challenged were mostly likely unwilling to listen or } \\
\text { not listen at all when challenged. }\end{array}$ \\
\hline
\end{tabular}

